\title{
HIV prevention through extended education encompassing students, parents, and teachers in Japan
}

\author{
Miyuki Nagamatsu $\cdot$ Takeshi Sato $\cdot$ \\ Aki Nakagawa $\cdot$ Hisako Saito
}

Received: 16 September 2010/Accepted: 27 December 2010/Published online: 22 January 2011

(C) The Japanese Society for Hygiene 2011

\begin{abstract}
Objectives We developed an extended HIV prevention program for students, parents, and school teachers, and then evaluated its effectiveness.

Methods The participants were 490 students, aged 13-14 years, attending four public junior high schools in Saga Prefecture, Japan. They were divided into two groups: control and intervention. All the students received group education by health professionals. In the control group, students received only two group education sessions given by health professionals. In the intervention group, there were three intervention components: parent education, teacher education, and student individual counseling by health professionals. Before and 3 months after the intervention, participants underwent evaluation of their frequency of communication about AIDS with parents or teachers, their knowledge of HIV/AIDS, and attitudes to sexual intercourse, self-esteem, and high-risk behavior.

Results A total of 135 students (80 boys and 55 girls) from the intervention group and 236 students (115 boys and 121 girls) from the control group participated in the evaluation 3 months after intervention. Adolescents in the intervention group showed more positive changes than those in the control group from baseline to follow-up. Intervention had a significant impact on the frequency of
\end{abstract}

M. Nagamatsu $(\bowtie) \cdot$ A. Nakagawa $\cdot$ H. Saito

Department of Maternal and Child Nursing,

Faculty of Medicine, Saga University,

5-1-1 Nabeshima, Saga City, Saga 849-8501, Japan

e-mail: nagamatm@cc.saga-u.ac.jp

T. Sato

Health Care Center, Saga University,

1 Honjo, Saga City, Saga 840-8502, Japan communication about AIDS with teachers $(p=0.027)$ and HIV/AIDS knowledge among females $(p=0.023)$, and intervention also had a significant impact on refusal of sexual activity by males $(p=0.045)$.

Conclusions These findings suggest that effective prevention of HIV might be achieved by an expanded education program for students and teachers such as that described, and individual counseling that takes into consideration the sexual differences of Japanese adolescents.

Keywords HIV prevention - Parent - Teacher .

Adolescent · Japan

\section{Introduction}

Japan has the most rapidly increasing number of AIDS patients among developed countries. The total number of HIV-infected persons in Japan, including those with AIDS, was 13,894 at the end of 2007, including 1,680 adolescents and young adults aged $\leq 25$ years, and the annual number of young persons with new HIV infection has risen from 47 in 1998 to 131 in 2007 [1]. Although individual counseling about prevention is provided at the time of HIV testing, the percentage of teenagers who undergo such testing is low. Based on the results of a 2005 survey by the Japanese Association for Sex Education [2], there has been a sharp increase in the numbers of Japanese teenage boys and girls with sexual experience, from 3.6 and $4.2 \%$ among early teenagers (aged 13-15 years) to 26.6 and $30.0 \%$ among late teenagers (aged 16-18 years), respectively. Accordingly, preventive education about HIV is important for early teenagers in Japan before they begin sexual activity. However, preventive education about HIV for young people is not carried out proactively in Japan at present. 
In the United States, the time of starting sexual activity was reported to depend on age, gender, race/ethnicity, socioeconomic status, religion, and the parent-child relationship. A relationship between the initiation of sexual activity by teenagers and parental child-rearing policies has been clarified [3]. In Japan, negative feelings about discussing sexual activity with teenagers and discomfort among Japanese parents and school teachers about taking part in investigations have resulted in fewer studies of teen sexual behavior and parent-adolescent relationships [4]. A survey of Japanese high school students in their late teens showed that parental supervision of children aged 16 or younger, parental disapproval of sexual behavior, and communication with parents about AIDS delayed the start of sexual activity by adolescents [5]. Other surveys performed in Japan have shown that sexual behavior among girls in their late teens is influenced by the "relationship between parents" and the "parent-adolescent relationship", whereas eating habits, dating partners, friends with sexual experience, and smoking and drinking influence both boys and girls [6]. Based on international and Japanese data for late teenagers, factors influencing the sexual behavior of early teenagers in Japan may include the family, school, friends, and partners.

Saito et al. [7] have pointed out that Japanese parents and teachers did not receive appropriate sex education when they were adolescents and often do not possess accurate knowledge about sexuality. In addition, the opportunities to learn about sexuality are limited during teacher training courses in Japan, although there are some exceptions. This results in a large number of teachers who have insufficient knowledge about sex education [7]. Tanomura [8] has reported that university-level teacher training courses in Japan provide education about sexual psychology, physiology, sexual health, and medical care as a special course, but few instructors who have specialized in sex education are available to provide education on this topic to university students. Therefore, many students receive little sex education when they are at university before becoming teachers, and thus have to acquire sex education skills and implement programs without assistance. Accordingly, sex education is still confused and at the trial-and-error stage in Japan [8].

With regard to preventive education about HIV in particular, students in their early teens receive little information from their families or junior high schools in Japan. A typical HIV education program provides basic knowledge by lecturers given in the third grade of junior high school, and the health and physical education teachers are usually responsible for HIV education. Because these teachers have the primary duty of teaching physical education and health, the time available for sex education is limited and the teachers cannot provide adequate HIV education. Tanomura [8] has indicated that training workshops for teachers are needed, which should be strengthened by educational support through the local community at each school so that such workshops can play an active role.

In 1999, the Japanese Ministry of Education, Culture, Sports, Science and Technology recommended "Cooperation between Schools and Pertinent Organizations/Community" in "The Concept and Approach of Sex education in Schools". Since then, junior high schools have often asked medical professionals to provide lectures for their students. However, it has been pointed out that some medical professionals provide education without sufficient understanding of the circumstances of adolescents or are unable to cooperate with the school adequately. In addition, the educational effect of a one-off lecture without evaluation is unknown [9]. Furthermore, Hasuo [10] has stated that sex education should not be managed by a gynecologist alone, and sex education lectures should not be the only method of sex education provided to junior high and high school students. Instead, sex education should involve parents at home; teaching staff at schools; and nurses, midwives, health nurses, gynecologists, and urologists from the medical field [10].

Until now, various HIV education programs have been created based on the Information-Motivation-Behavioral skills model, social recognition theory, and the life skills model. However, Wright [11] has pointed out that uniform group education for students has little effect as a strategy for reducing the incidence of pregnancy and sexually transmitted diseases (STDs). Intervention to prevent HIV and AIDS among adolescents did not achieve the goals of increasing HIV and AIDS knowledge, changing attitudes, improving negotiation and communication skills, or influencing positive behavior such as consistent condom use, abstinence, or reducing the number of sexual partners [12]. Ingram et al. [13] selected five evidence-based HIV prevention programs [14-18]. The programs were similar in a number of ways. Each program: (1) targeted adolescents or preadolescents; (2) focused on reduction of sexual risk behavior; (3) was delivered in small-group formats for 5-30 adolescents; (4) was delivered with ethnic minority populations; and (5) included multiple sessions (from 7 to 20 sessions). All programs were skill-focused and utilized cognitive-behavioral principles. These programs selected safer choices [14] for school-based programs that included HIV prevention. We believe that multiple behavioral interventions based on social recognition theory are necessary for early adolescents to reduce the risk of HIV transmission in Japan.

Of note, some studies have revealed that the risk of contracting STDs is lower for students with a high level of self-esteem. Salazar et al. [19] reported that females with a 
higher level of self-esteem participated in frequent communication with their parents and their partners, and that they were able to discuss condom use with their partners when they had sex. In addition, Denny and Young [20] reported that students who attended classes designed to delay sexual activity by focusing on improvement of selfesteem commenced sexual activity at a later age in comparison to those who did not attend such classes. These reports suggest that programs to promote the self-selection of safe behavior may be useful for students with a high risk of pregnancy or STD, in order to improve their self-esteem. Also, recent Japanese studies have shown that young people with someone to consult have higher self-esteem than young people without someone to consult [21]. We consider it essential to recognize the importance of selfesteem and self-protection for selecting safe HIV prevention strategies. However, the frequency of communication with parents decreases among adolescents. In particular, speaking with parents about sex and HIV is rare in Japan, and adolescents also have few people to consult to share their sex-related concerns $[4,5]$. Therefore, to improve the self-esteem of young Japanese, we consider it important for intervention to increase their communication with parents and also to provide a chance for them to consult health professionals about concerns which they cannot express to other people. Furthermore, a new public health approach for the prevention of HIV/AIDS in Japan has indicated that HIV should be recognized as "a disease that anyone can catch". As such, multiple interventions are recommended to promote individual health as well as to contribute to public health [22]. Accordingly, we consider that various HIV prevention programs should be developed as soon as possible in consideration of both overseas findings and the Japanese cultural and educational environment.

The objective of our program is to prevent an increase in the number of Japanese young people with HIV infection. This program was designed to delay the initiation of sexual activity among Japanese junior high school students in their early teens. To achieve this objective, we prepared an education program on the prevention of HIV infection which is provided at school for 2 years to Japanese junior high school students who have not already had sex. This program has been prepared to target factors that influence the sexual behavior of young adolescents through education by parents and school teachers, with support by health professionals. It is based on the concept model of self-esteem and social cognitive theory, and consists of three components, which are parent education, teacher education, and student individual counseling by health professionals. The objective of our study was to evaluate the effectiveness of this extended education program.

\section{Methods}

Participants

The participants were students attending four public junior high schools located in Saga Prefecture, Japan, which has a population of 866,000 and an area of $2,439 \mathrm{~km}^{2}$. The schools were selected at random, with two schools each for the control group and the intervention group. A survey of all students was conducted anonymously by questionnaire on two occasions between December 2007 and December 2008. The first survey was conducted in December 2007. Intervention involved 2 grades (among junior high schools) - second grade from December 2007 to March 2008 and third grade from April 2008 to July 2008. The follow-up survey was conducted in December 2008. There were a total of 490 students at the four participating schools in the second year of junior high school who were aged 13-14 years. There were 298 students at the schools providing the control group and 192 students at the schools supplying the intervention group.

\section{Program procedure}

The schools belonging to the intervention group are listed in Table 1. The procedures for intervention and control schools are outlined in Fig. 1. Group education by health professionals was provided for students in both the intervention and control groups.

Intervention group

The three intervention components (see Table 1) were parent education, teacher education, and student individual counseling by health professionals.

\section{Parent education}

The objective of parent education was to improve the selfesteem and self-protection of young people by helping their parents understand the changes affecting their children during puberty and how to cope with them.

Education for parents A midwife, a gynecologist, and two school nurses provided training for parents/guardians before assigning homework that involved both parents and students.

Homework assignments for parents and students Assignments were completed at home to improve communication between parents and students. School nurses gave the students the homework assignments. 


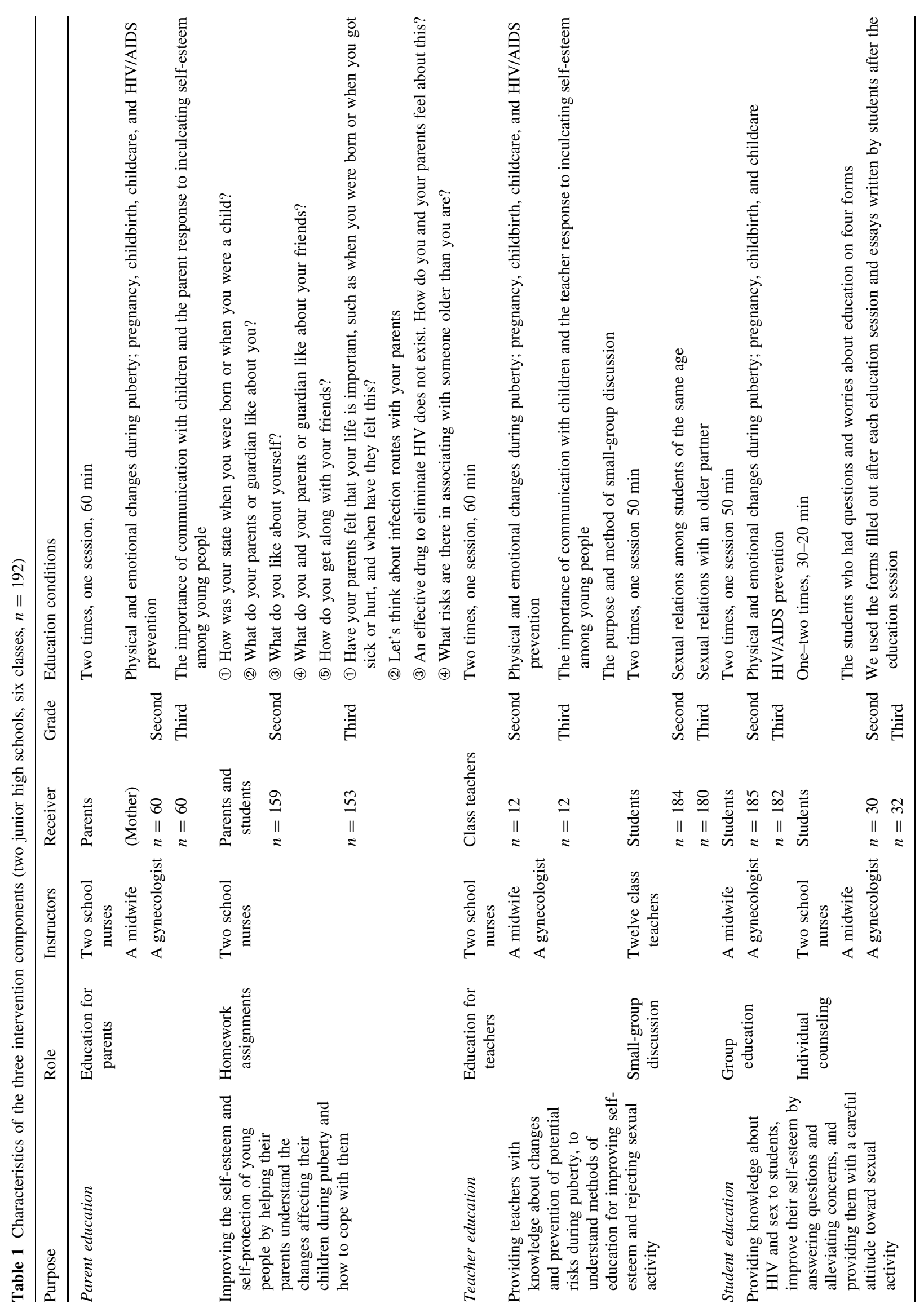


Fig. 1 Process of the intervention and the control
Intervention group

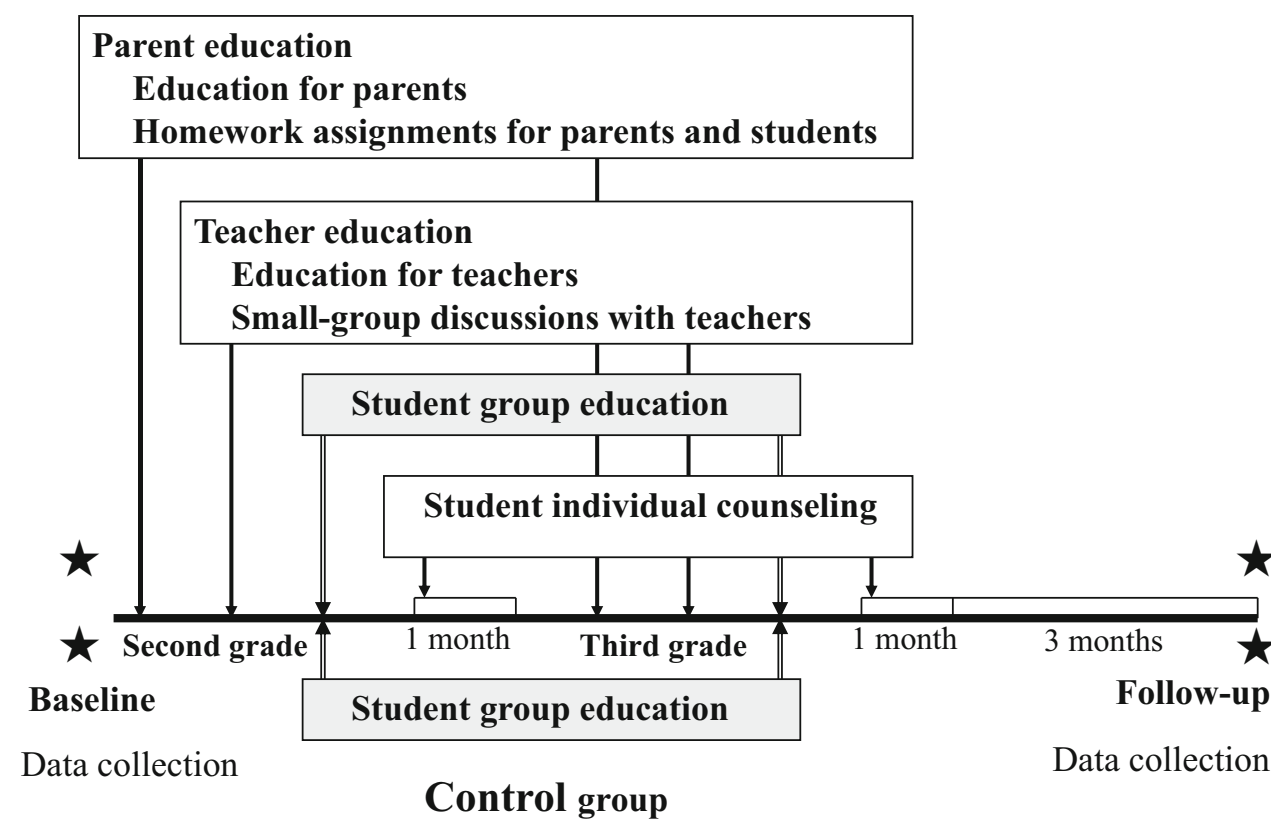

\section{Teacher education}

The objective of teacher education was to provide teachers with knowledge about changes and prevention of potential risks during puberty, to understand methods of education for improving self-esteem and rejecting sexual activity, and to teach their students how to improve self-esteem and refuse sexual activity.

Education for teachers A midwife, a gynecologist, and two school nurses provided training for class teachers before small-group discussions.

Small-group discussions with teachers Two small-group discussions were conducted by class teachers after training. The objective was to improve communication skills related to refusal of sexual activity and negotiations with regard to sexual relations. The students also performed role-playing exercises. If examples of dangerous behavior arose during the exercises, the students were asked to think of ways to avoid such behavior and to fill out forms listing their ideas. Students wrote essays about their impressions after each small-group discussion.

\section{Student education}

The objective of professional counseling was to provide knowledge about HIV and sex to students, improve their self-esteem by answering questions and alleviating concerns, and to provide them with a careful attitude toward sexual activity.
Student group education A gynecologist or a midwife gave two types of group education to the students, who wrote essays about their impressions after each type of group education.

Student individual counseling Based on data from four sources-(1) the homework assignment, (2) the essay written after group education, (3) the small-group discussion forms, and (4) the essays written after the discussions-school nurses, midwives, and gynecologists selected students who had questions and worries about their education. These students were given individual counseling by a school nurse, midwife, or gynecologist after regular school hours.

\section{Control group}

\section{Student group education}

A gynecologist or a midwife gave two group education sessions to the students. After the 3-month follow-up survey, information was provided to teachers and parents, and individual counseling was provided for adolescents who requested it.

\section{Study procedure}

The authors distributed an explanatory document, the questionnaires, and consent forms to the school teachers. The explanatory document contained instructions on how to distribute and recover the questionnaires. It emphasized 
the confidentiality of material in the questionnaires, which were sealed before recovery. The consent form contained a detailed explanation of the objectives of the research, the confidentiality of all information, the freedom to refuse to participate, and contact information for the researchers. Before the survey was conducted, a letter and a consent form were distributed to the parents through the students. For students without parents, we obtained the consent of their guardians [the adult(s) responsible for their upbringing]. Students consented after parental consent. If a student did not want to participate in the survey, the student could refuse to hand the consent form to his/her parents or guardians. The student could refuse to participate in the survey, even if his/her parents or guardians had consented to the participation. The survey was conducted only when both students and their parents or guardian gave consent for the survey. The students could receive the education if they wanted. Students were not made to undergo education if they refused. Students were also not made to provide certain data if they refused.

To all students, including those who had consented to participate in the survey, instructors at the large- and smallgroup education sessions explained at the beginning that students could leave the classroom if they did not feel like participating. Students were also told that the forms and essay sheets collected at each session would be checked by the instructor, and that a subsequent individual counseling session could be provided for selected students. Students were told that they did not have to submit the forms/essays unless they consented. Parents or students who did not consent did not have to complete or submit the homework forms. Those who agreed to participate signed and submitted the forms at the end of the session. Individual counseling sessions were provided after the school nurses had obtained prior consent from the students. Instructors explained at the beginning of individual sessions that students could leave in the middle if they so wished. The study protocol was approved by the Ethics Committee of Saga University Medical School. The approval of each school principal was also obtained.

\section{Investigations}

\section{Frequency of communication about AIDS with parents or teachers}

A Japanese study showed that communication by children with their parents about AIDS when the children were 16 or younger delayed the start of sexual activity by adolescents [5]. We asked students about their frequency of communication about AIDS for assessment before intervention and 3 months after intervention. "Did you talk to your parents/guardians about AIDS during the past
Table 2 HIV/AIDS knowledge

1. The AIDS virus cannot be transmitted by coughing

2. The AIDS virus cannot penetrate healthy skin

3. There is no concern over infection if sexual activity is limited to one specific partner

4. People infected with the AIDS virus look unhealthy

5. Sexual intercourse has the danger of HIV infection

6. The routes of infection are through the blood, from sexual intercourse, and from mother to child

7. There is no possibility of infection if there are no abnormalities in the sexual organs or the surrounding area

8. Sexual intercourse is completely safe if a condom is used

9. The period for the development is long after a person is infected with HIV. While it differs according to the individual, it ranges from five to 15 years, and averages 10 years

10. The onset of AIDS after infection with HIV can be delayed due to advances in treatment with drugs

3 months?" In addition, we added the question: "Did you talk to any teachers at your school about AIDS in the past 3 months?" For the questions that we devised, students selected one of four alternatives: $1=$ never, $2=$ seldom, $3=$ sometimes, $4=$ often.

\section{Knowledge of HIV/AIDS}

The scale to evaluate knowledge of HIV/AIDS developed by Kelly et al. consisted of 40 items [23]. In 2003, this scale was translated into Japanese by Matsumoto and Takeda [24]. They excluded 20 items that did not accord with the Japanese culture and created a Japanese version of such a scale that contained 30 items, i.e., 20 items from Kelly's scale and an additional 10 items regarding current knowledge of HIV and AIDS. They reported that 14 of the 30 items showed a high level of appropriateness in evaluating knowledge of HIV/AIDS ( $\alpha$-coefficient for reliability $=0.67$ ) [24]. We used the scale with permission from the copyright holder. Our preliminary study in 13- to 14-year-old participants showed that the response rate for 4 of the 14 items was low. Therefore, we used a simplified version of the scale, with 10 items. We demonstrated that the scale was appropriate in 13- to 14-year-old students for this study $(\alpha=0.69)$ (Table 2$)$.

\section{Self-esteem}

We used the general self-esteem scale $(\alpha=0.78)$ developed by Rosenberg [25] for assessment before intervention and 3 months after intervention. This scale has 10 items. It was translated into Japanese by Hoshino [26], and its suitability has been demonstrated $(\alpha=0.75)$. This scale is commonly used for school education in Japan. It is often used for surveys of high-risk behavior among adolescents 
in Japan. It was also used to survey the current level of sexual activity and relevant factors among Japanese junior high school and high school students in 2007 [27]. For each item, a participant was instructed to select one of four options: (1) strongly agree, (2) agree, (3) disagree, and (4) strongly disagree.

\section{Attitude to rejecting sexual intercourse}

Currently, there is no validated Japanese version of scales that can measure attitudes to sexual intercourse. Therefore, two original questions were devised to assess the attitude of junior high school students to rejecting sexual intercourse. In the present study they were used as single and separate questions.

These two questions were as follows:

1. Attitude to rejecting sexual activity

"What do you think about having sex when you are in junior high school?" For this question, students selected one answer from two alternatives: "I do mind (reject sexual activity)." or "I don't mind (accept sexual activity)."

2. Confidence about rejecting sexual advances

"Do you have the confidence to reject sexual advances when you are asked?" For this question, students selected one answer from two alternatives; "Yes (I have the confidence to reject advances)" or "No (I do not have enough confidence to reject advances)."

High-risk behavior (alcohol consumption, cigarette smoking, and sexual intercourse)

Inoue et al. [6] have shown that smoking and drinking have an influence on the sexual behavior of both boys and girls in Japan. We used the following three original questions to evaluate high-risk behavior before and 3 months after intervention with respect to alcohol consumption, cigarette smoking, and sexual intercourse during the past 3 months.

(1) Have you consumed alcohol within the last 3 months?

(2) Have you smoked within the last 3 months? (3) Have you had sexual intercourse within the last 3 months? The $\alpha$-coefficient for assessing the reliability of these questions was 0.61 . In the present study, we used these questions singly and separately.

\section{Statistical analysis}

Data were collected at two points in time and thus provided repeated measures of the frequency of communication about AIDS, the knowledge of HIV/AIDS, self-esteem, and behavior. The mean and standard deviation of the total score were calculated for each scale. The frequency of communication about AIDS, knowledge of HIV/AIDS, and self-esteem were compared between baseline and 3 months after intervention in the intervention group and the control group by using Student's $t$-test. We also analyzed the attitude to sexual intercourse and the rates of alcohol consumption, cigarette smoking, and sexual activity using the $\chi^{2}$ test. In addition, we compared the frequency of communication about AIDS; knowledge of HIV/AIDS; self-esteem; attitudes to sexual intercourse; and the rates of alcohol consumption, cigarette smoking, and sexual activity between the intervention group and the control group at baseline and follow-up. Repeated measures were treated as an additional level in multilevel analysis. In order to assess whether there was a significant interaction effect between measures of the effect of intervention and gender, threeway analysis of variance (ANOVA) was performed.

Multiple regression analysis was used to analyze numerical data (the frequency of communication about AIDS, knowledge of HIV/AIDS, and self-esteem) for each gender. Logistic regression models were used to analyze categorical variables (attitude to sexual intercourse and the rates of alcohol consumption, cigarette smoking, and sexual activity) for each gender. Two types of significance data are provided, which are the results of tests indicating whether the difference of each variable between baseline and follow-up was statistically significant for each gender, and tests indicating whether the impact of intervention was statistically significant for each gender. The Statistical Package for the Social Sciences (SPSS 14.0) was employed for all analyses. Significance of differences was accepted at $p<0.05$. When logistic regression analysis was performed, the odds ratio and the $95 \%$ confidence interval were calculated to assess the differences between baseline and follow-up, as well as the differences between the intervention group and the control group.

\section{Results}

\section{Survey findings}

Table 3 shows the survey results (mean scores and percentages) at baseline and follow-up for the intervention group and the control group. The questionnaire was completed before intervention by 423 students $(86.3 \%)$ who gave informed consent to the survey. There were 211 males (49.9\%) and 212 females (50.1\%). The mean age of the 423 students before intervention was $13.7 \pm 0.45$ years (mean $\pm \mathrm{SD}$ ). At the intervention group schools, there were 192 students, of whom 164 (85.4\%) gave informed consent and took part in the survey, including 87 males 
Table 3 Comparative knowledge, self-esteem, attitudes, and behavior among the adolescent intervention group and control group from baseline to follow-up

\begin{tabular}{|c|c|c|c|c|c|c|c|c|}
\hline \multirow{3}{*}{$\begin{array}{l}\text { Number of subjects at } \\
\text { baseline and follow-up } \\
\text { Overall (male/female) }\end{array}$} & \multicolumn{3}{|l|}{ Intervention } & \multicolumn{3}{|l|}{ Control } & \multirow{2}{*}{\multicolumn{2}{|c|}{$\frac{\text { Interaction }}{\text { Baseline follow-up }}$}} \\
\hline & \multirow{2}{*}{$\begin{array}{l}\text { Baseline } \\
164(87 / 77)\end{array}$} & \multirow{2}{*}{$\begin{array}{l}\text { Follow-up } \\
135(80 / 55)\end{array}$} & \multirow{2}{*}{$\begin{array}{l}\text { Baseline } \\
\text { versus } \\
\text { follow-up } \\
p \text { value }\end{array}$} & \multirow{2}{*}{$\begin{array}{l}\text { Baseline } \\
259(124 / 135)\end{array}$} & \multirow{2}{*}{$\begin{array}{l}\text { Follow-up } \\
236(115 / 121)\end{array}$} & \multirow{2}{*}{$\begin{array}{l}\text { Baseline } \\
\text { versus } \\
\text { follow-up } \\
p \text { value }\end{array}$} & & \\
\hline & & & & & & & $\begin{array}{l}\text { Intervention } \\
p \text { value }\end{array}$ & $\begin{array}{l}\text { Gender } \\
p \text { value }\end{array}$ \\
\hline \multicolumn{9}{|c|}{ Frequency of communicating about AIDS } \\
\hline $\begin{array}{l}\text { Talking with parents mean } \\
\text { [(SD) min-max }]\end{array}$ & $1.2(0.4) 1-3$ & $1.2(0.6) 1-3$ & 0.179 & $1.3(0.5) 1-3$ & $1.3(0.6) 1-3$ & 0.117 & 0.768 & 0.181 \\
\hline $\begin{array}{l}\text { Talking with teachers mean } \\
\text { [(SD) min-max }]\end{array}$ & $1.2(0.5) 1-4$ & $1.7(0.9) 1-4$ & $<0.001$ & $1.4(0.7) 1-4$ & $1.6(0.6) 1-4$ & 0.056 & $<0.001$ & 0.012 \\
\hline $\begin{array}{l}\text { HIV/AIDS knowledge mean } \\
\text { [(SD) min-max] }\end{array}$ & $6.5(2.1) 0-10$ & $8.1(1.6) 3-10$ & $<0.001$ & $6.8(2.3) 0-10$ & $7.8(1.7) 1-10$ & $<0.001$ & 0.028 & 0.026 \\
\hline $\begin{array}{l}\text { Self-esteem mean } \\
{[(\mathrm{SD}) \text { min-max }]}\end{array}$ & $24.4(5.0) \quad 10-37$ & $26.2(5.0) 16-40$ & 0.003 & $24.3(5.4) \quad 10-37$ & $24.8(5.4) 10-40$ & 0.298 & 0.107 & 0.056 \\
\hline \multicolumn{9}{|l|}{ Attitude to sexual intercourse } \\
\hline $\begin{array}{l}\text { Rejection of sexual } \\
\text { activity }(\%)\end{array}$ & 79.6 & 86.0 & 0.199 & 81.9 & 77.1 & 0.235 & 0.034 & 0.030 \\
\hline $\begin{array}{l}\text { Confidence in rejecting } \\
\text { sexual advances }(\%)\end{array}$ & 82.2 & 73.6 & 0.130 & 79.0 & 79.7 & 0.904 & 0.186 & 0.440 \\
\hline \multicolumn{9}{|l|}{ Risky behavior } \\
\hline Alcohol use (\%) & 13.1 & 15.2 & 0.735 & 21.2 & 17.7 & 0.356 & 0.463 & 0.008 \\
\hline Cigarette tobacco use (\%) & 1.9 & 1.5 & 1.000 & 4.9 & 3.9 & 0.660 & 0.857 & 0.737 \\
\hline Sexual activity (\%) & 0.7 & 1.5 & 1.000 & 1.7 & 1.5 & 1.000 & 0.538 & 0.584 \\
\hline
\end{tabular}

Analyses used Student's $t$-test or the $\chi^{2}$ test for differences in each characteristic between baseline and follow-up. Three-way analysis of variance (ANOVA) was used for analysis in order to assess whether there was a significant interaction effect between measures of the effect of intervention and gender

(53.0\%) and 77 females (47.0\%). At the control group schools, there were 298 students, of whom 259 (86.9\%) gave informed consent to the survey, including 124 males (47.9\%) and 135 females (52.1\%). Of the 423 students who participated in the survey before intervention, 371 (88.8\%) participated in the second survey at 3 months after intervention, including 135 students $(82.3 \%)$ from the intervention group and 236 students $(91.1 \%)$ from the control group.

\section{Effect of intervention}

We compared the results between baseline and follow-up for the intervention group (Table 3). The frequency of communication about AIDS with parents did not change for either the intervention group or the control group. However, the frequency of communication about AIDS with teachers increased in the last 3 months for the intervention group $(p<0.001)$. After 3 months, in the intervention group, the mean scores for HIV and AIDS knowledge $(p<0.001)$ and for self-esteem $(p=0.003)$ were significantly higher than at baseline. When we compared the results between baseline and follow-up for the control group, the mean scores for HIV and AIDS knowledge $(p<0.001)$ were significantly higher than at baseline. Both the intervention and control groups showed some positive results at the baseline and follow-up.

There was a significant interaction effect of the intervention involving an impact on the frequency of communication about AIDS with teachers $(p<0.001)$, HIV/AIDS knowledge $(p=0.028)$, and refusal of sexual activity $(p=0.034)$. In addition, there was a significant interaction effect of gender with an impact on the frequency of communication about AIDS with teachers $(p=0.012)$, HIV/ AIDS knowledge $(p=0.026)$, refusal of sexual activity $(p=0.030)$, and alcohol use $(p=0.008)$.

Influence of gender

For males and females in both groups, results were compared between baseline and follow-up by multiple regression models or logistic regression models (Table 4). For males and females in both groups, the frequency of communication about AIDS with parents did not change. 
At follow-up, for males and females in the intervention group and females in the control group the frequency of communication about AIDS with teachers increased in the last 3 months. Also, the interaction with the intervention was significant among females for the impact on the frequency of communication about AIDS with teachers $(p=0.027)$.

The scores for HIV and AIDS knowledge $(p<0.001)$ at follow-up were significantly higher than those at baseline in males from both groups. However, the interaction with the intervention was not significant for males with respect to HIV and AIDS knowledge. The scores for HIV and AIDS knowledge were significantly higher at follow-up in girls from the intervention group $(p<0.001)$ and the control group $(p=0.019)$. Also, the interaction with the intervention was significant for the impact on HIV/AIDS knowledge in females ( $p=0.023)$.

The score for self-esteem was significantly higher at follow-up than at baseline in females from the intervention group $(p=0.029)$ and the control group $(p=0.036)$. However, no significant interaction of self-esteem with the intervention was detected for either gender. In addition, the percentage of males refusing sexual activity was significantly lower $(p=0.020)$ at follow-up than at baseline in the control group. However, boys from the intervention group showed a higher refusal rate of sexual activity at follow-up than at baseline. Intervention had a significant impact on refusal of sexual activity by males $(p=0.045)$. The intervention had no significant impact on other variables in either males or females.

\section{Discussion}

This study suggested that adolescents showed more positive changes in measures of attitudes to sexual activity and HIV/AIDS knowledge with an expanded intervention education program for students, parents, and school teachers. There were gender differences in the effects of the intervention. Among females, the intervention had a significant impact on the frequency of communication about AIDS with teachers and HIV/AIDS knowledge, and in males it had a significant impact on refusal of sexual activity.

We consider that the differences between males and females might be related to communication and differing values about sexual activity between male and female adolescents in Japan. It has been reported that the percentage of students who have had sex increases with age among Japanese junior high school and high school students, and young males who are sexually active and have strong sexual desires take a greater interest in sex and are more positive toward sexual behavior than young females who are passive with respect to sex [2]. For female students who only had a slight interest in sex, a program that addressed their questions and concerns by increasing the opportunities for education from teachers was more effective for providing accurate knowledge than group education only. The present study showed that for females in the intervention group, the frequency of communication about AIDS with teachers had increased at the 3 month follow-up compared with this communication aftergroup education for students. On the other hand, male students were more likely to have a strong interest in sex, so that even group education led to an improvement of knowledge. Among the young females with a higher risk of pregnancy and sexual abuse, the percentage of students refusing sex was increased by group education in both the intervention and control groups. On the other hand, among the young males showing a decrease in rejection of sex with age, there was an increase in the percentage of students refusing sex that was probably due to the intensified education provided by this program (including education for teachers, as well as individual counseling).

Kirby et al. [28] created a School Health Promotion Council that consisted of school teachers, students, parents, administrators, and members of the community. They reported an increase in the number of male students who used condoms after intervention by Council programs, but they also reported there was no effect on female students. Flay et al. [29] conducted a School Community Intervention Program that lowered the rate of increase in sexual activity among male students aged 10-13 and also increased condom use, although these effects were not observed among female students. The results of such studies indicate that there is a limit to the effectiveness of group education for preventing HIV infection because of the influence of student attitudes, gender, and individual differences in sexual behavior. It has been reported that the effects of these programs show differences between males and females. For example, an education program designed to increase the use of condoms had a definite effect in males, but was ineffective in females.

In the sex education program delivered by life skill training for junior high school students in Japan, nine educational sessions of different styles conducted by medical experts and school staff were compared. Significant improvements were seen in self-esteem, willingness to study, and attitudes toward sexual information among male students, as well as in willingness to study and attitudes toward sexual information among female students [30]. Thus, it was clarified that an intervention with the program had an effect on self-esteem, willingness to study, and the attitude to sexual information among males, as well as on study and the attitude to sexual information among females. 


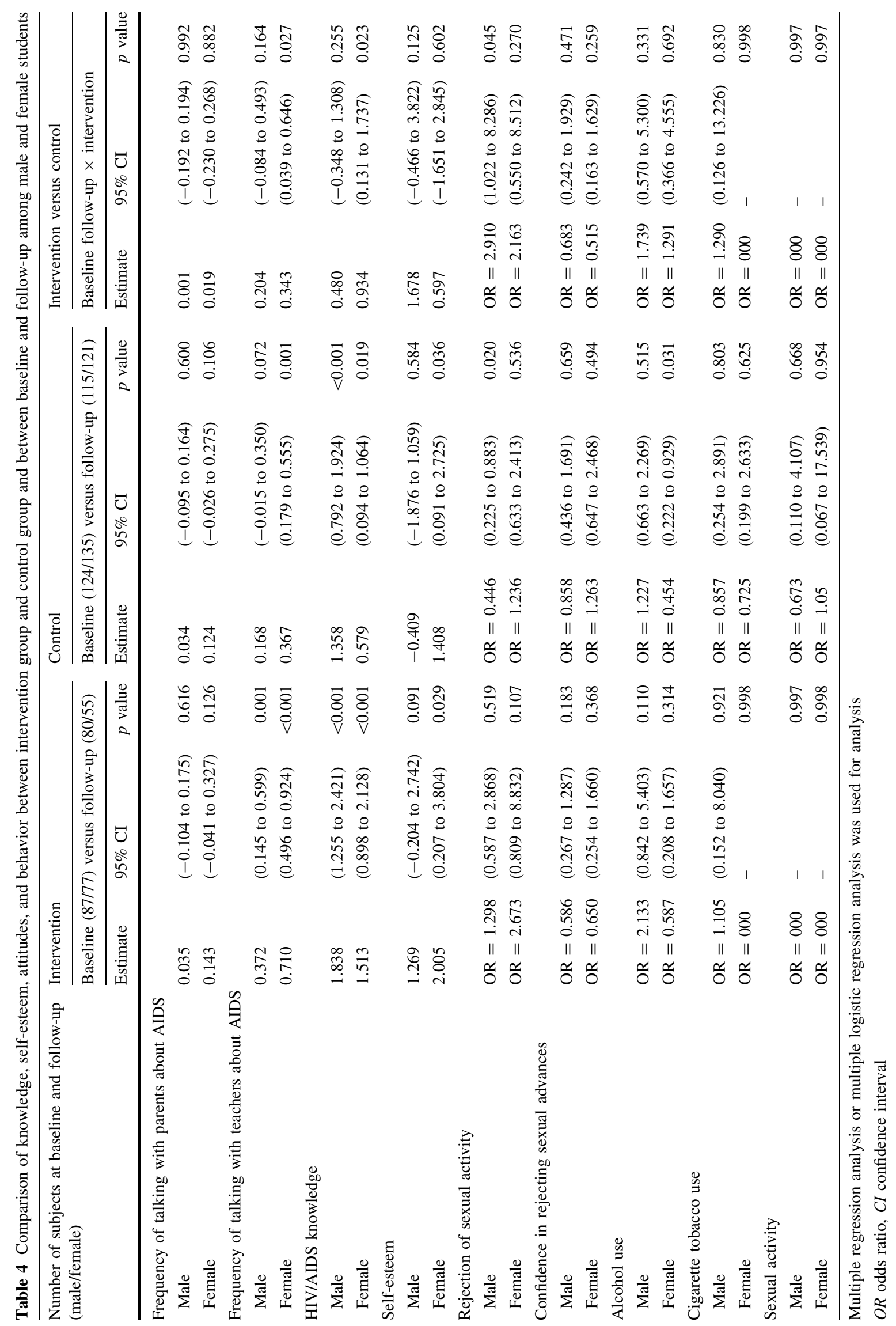


Saito et al. [7] have reported that individualized counseling in response to student requests requires coordination with medical institutions. In addition to counseling by nurse teachers at schools, regular visits by medical and healthcare personnel to schools are recommended to provide counseling on specific issues related to sexual intercourse. Similarly, counseling provided by the local community is advised. However, these activities are not sufficiently available in Japan. In the present study, we provided an extended program, with parental training, teacher training, more education for adolescents, and individual counseling for students who had questions or concerns about the information they received. As a result of the individual counseling, we discovered some students with incorrect knowledge about the routes of HIV infection and prevention of infection. We also discovered that male students who accepted sexual intercourse at junior high school believed that their peers also accepted sex. Further, we found that male students who lacked the confidence to refuse sex also wanted to have sexual intercourse if they had the opportunity. It was possible that some of the students who were having sexual intercourse could contract STDs. For students who had begun sexual activity, we provided education about HIV/STDs, explained the need for testing, and recommended that they undergo testing at a public health center or medical institution.

Small-group adolescent discussion and individualized education showed us how the students were influenced by the values of their peers and how this shaped their attitude to sexual intercourse. Male students also reported that the behavior of their peers contributed greatly to the decision about when to have sex for the first time. Larsson and Svedin [31] reported that adolescents began sexual relations with partners close to their own age, and that $93 \%$ of young people first had sex with someone within 2 years of their own age. Further, Papadopoulos et al. [32] reported that most adolescent females initially did not think they would have sexual intercourse when engaged in social interaction with a male, but had sexual intercourse unexpectedly. It is necessary to emphasize to students involved in male-female interactions the ever-present risk of unwanted pregnancy and STDs caused by sexual intercourse as a way of reducing such risks.

A previous Japanese study showed that high school students who received peer counseling by university students had a higher sense of self-esteem than adolescents who did not receive such counseling. However, the risks of pregnancy and STDs were not significantly lower than those in the adolescents without such education [33]. We believe that an individualized approach to students by school nurses or medical professionals is required. During our individual counseling sessions, we informed the students that more of their peers disapproved of sexual activity than approved.
Accordingly, the significant increase in male students who rejected sexual activity after individual education may have occurred because they recognized that their preconceived ideas about sexual behavior were erroneous. We also suggested to the students during their individual education sessions that they should not rush into sexual activity because it was easy for adolescents to have sexual intercourse with someone close to their own age, but that there was a risk of unwanted pregnancy and STD as a result of such relations. The present study suggested that a stronger and persistent influence on adolescents was achieved through multiple methods of intervention, including education for teachers and individual counseling.

The frequency of communication about AIDS with parents did not change for either males or females in our study. Takedomi et al. [34] reported that Japanese parents of new college students answered that they could easily discuss physical growth and pregnancy with their children, but they answered that it was difficult to discuss HIV/ AIDS, sexual behavior, and contraception for children younger than 18 years old. There is a negative feeling about communication on sexual matters between parents and adolescents because sex and sexual relations are topics less easily discussed between parents and adolescents and between men and women in Japan than elsewhere. In addition, Hiraoka [35] identified clear differences in the awareness of sex by generation between junior high school students and their parents. We consider that parents and adolescents did not conduct high-level communications about sexual matters, including AIDS, in the home because of the Japanese cultural background in which parents find it difficult to educate adolescents about sexual matters. There is particular resistance to talking about sexual matters between adolescents and parents at home in Japan. It may be necessary to educate for parent of the child before adolescence to be able to talk about sexual matters without resistance. Based on the results of the present study, we think it is important to enhance sex education at school, and maintain good communications with each family member at home.

Furthermore, we found that the students who had begun having sexual intercourse were more likely to have problems at home, such as parents who were too lenient or too strict. It has been reported that the age of initiation of sexual activity is influenced by the parent-child relationship [5]. Saito et al. [7] stated that, when interacting with individual students, personal information should be handled with care and contact with the parents should be dependent upon agreement with the students. In the future, considering the existence of various problems with parentchild relationships, we think that it may be necessary to provide individual counseling for the parents of high-risk students. 
Limitations of the study

It would have been preferable to establish a control group with absolutely no intervention, but the schools would not permit two surveys to be carried out without education also being provided to the students. After the 3-month followup survey, information on the control group was given to teachers and parents, and individual counseling was provided for adolescents who requested it. Because some parents and guardians did not participate in the education for parents, we provided health information sheets for all parents and guardians after the education program. To improve the participation rate of parents and guardians, a better method should be found for a future program. We asked the students about their frequency of communication about AIDS with parents for assessment before the intervention and 3 months after the intervention. However, we could not collect any data from the parents or guardians, or from the teachers. Due to the Japanese culture, parents and school teachers have a tendency to resist surveys on sexual matters and training conducted by external organizations. Future studies should investigate how to survey parents and teachers in order to devise better methods. Also, it would have been informative to conduct long-term follow-up after our intervention, but this was not possible because the participating students soon graduated from their junior high schools and moved to high schools.

\section{Conclusion}

The efficacy of an extended program of education, including education for parents and teachers, in-depth education for adolescents, and individual counseling, was evaluated among students aged 13-14 attending four public junior high schools in Saga Prefecture, Japan. Female students from the intervention group showed a better frequency of communication about AIDS with teachers, and better AIDS and HIV knowledge than female students from the control group. Male students from the intervention group showed less acceptance of sexual activity at 3 months after intervention than male students from the control group. We consider that the differences between males and females might be related to differences in communication and differing values about sex between male and female adolescents in Japan. In future, it will be important to promote adolescent education by maintaining close ties with the school and family, and by providing individual counseling that takes into consideration the sexual differences in Japanese adolescents.

Acknowledgments The authors would like to thank the students, parents/guardians, school nurses, and teachers at the participating schools for allowing us to conduct this research. We would also like to thank the following gynecologists for their cooperation: Drs. R. Okuma, Y. Okuma, R. Tomonari, and S. Yoshimura.

\section{References}

1. Ministry of Health, Labor and Welfare AIDS Trend Committee. 2008. Retrieved July 102010 from http://api-net.jfap.or.jp/status/ 2007/07nenpo/nenpo_menu.htm.

2. Japanese Association for Sex Education. National white paper of the youth: Survey of Japanese young sexual behavior 2005 . Plenum Press Tokyo; 2007 (article in Japanese).

3. Meschke LL, Bartholomae S, Zentall SR. Adolescent sexuality and parent-adolescent processes: promoting healthy teenage choices. J Adolesc Health. 2002;31:264-79.

4. Nagamatsu M, Ozaki I, Takedomi Y, Sato T. Literature review on programs about HIV and sexuality for parents of adolescents. J AIDS Res. 2007;9:158-66 (article in Japanese).

5. Nagamatsu M, Saito H, Sato T. Factors associated with gender differences in parent-adolescent relationships that delay first intercourse in Japan. J Sch Health. 2008;78:601-6.

6. Inoue M, Nishihira T, Kakazu I. A study of high school students' sexual behavior and its influencing factors. Adolescentology. 2005;22:495-503 (article in Japanese).

7. Saito M, Inokuchi I, Takamura H, Hiraoka T, Murase K, Kimura Y, Horikuchi M. The sexual education at adolescence and its preferable role. Adolescentology. 2009;27:351-60.

8. Tanomura Y. Has the turning point in sexual education come?: From the point of view of sexual education. Adolescentology. 2006;24:26-9 (article in Japanese).

9. Iwamuro S. Has the turning point in sexual education come?: From the point of view of community health. Adolescentology. 2006;24:35-9 (article in Japanese).

10. Hasuo Y. Necessity of sex education and promotive activities for oral contraception. Obstet Gynecol Ther. 2009;99:639-42 (article in Japanese).

11. Wright MT. Beyond risk factors: trends in European sex research. J Psychol Hum Sex. 1998;10:7-18.

12. Magnussen L, Ehiri JE, Ejere HO, Jolly PE. Interventions to prevent HIV among adolescents in less developed countries: are they effective? Int J Adolesc Med Health. 2004;16:303-23.

13. Ingram BL, Flannery D, Elkavich A, Rotheram-Borus JM. Common processes in evidence-based adolescent HIV prevention programs. AIDS Behav. 2008;12:374-83.

14. Coyle K, Basen-Engquist K, Kirby D, Parcel G, Banspach S, Collins J, et al. Safer choices: reducing teen pregnancy, HIV, and STDs. Public Health Rep. 2001;116:82-93.

15. Jemmott JB, Jemmott LS, Fong GT. Reductions in HIV riskassociated sexual behaviors among black male adolescents: effects of an AIDS prevention intervention. Am J Public Health. 1992;82(3):372-7.

16. Rotheram-Borus MJ, Song J, Gwadz M, Lee MB, Van Rossem R, Koopman C. Reductions in HIV risk among runaway youth. Prev Sci. 2003;4(3):173-87.

17. St.Lawrence JS, Brasfield TL, Jefferson KW, Alleyne E, O'Bannon RE, Shirley A. Cognitive-behavioral intervention to reduce African American adolescents' risk for HIV infection. J Consult Clin Psychol. 1995;63(2):221-37.

18. Stanton BF, Li X, Ricardo I, Galbraith J, Feigelman S, Kaljee L. A randomized, controlled effectiveness trial of an AIDS prevention program for low-income African-American youths. Arch Pediatr Adolesc Med. 1996;150(4):363-72.

19. Salazar LF, Crosby RA, Diclemente RJ, Wingood GM, Lescano CM, Brown LK. Self-esteem and theoretical mediators of safer 
sex among African American female adolescents: implication for sexual risk reduction interventions. Health Educ Behav. 2005;32:413-27.

20. Denny G, Young M. An evaluation of an abstinence-only education curriculum: an 18-month follow-up. J Sch Health. 2006; 76:414-22.

21. Kurata M. Relation between self-affirmation and the existence of confidants for high school and university students. Adolescentology. 2008;26(2):257-60 (article in Japanese).

22. Kodama T. New public health approach for HIV/AIDS. J AIDS Res. 2010;12:18-27 (article in Japanese).

23. Kelly JA, St Lawrence JS, Hood HV, Brasfield TL. An objective test of AIDS risk behavior knowledge: scale development, validation, and norms. J Behav Ther and Exp Psychiatry. 1989;20: 227-34.

24. Matsumoto J, Takeda B. Comparative study on self-efficacy on preventive behavior toward HIV infection by different intervention approaches. Adolescentology. 2003;21:379-87.

25. Rosenberg M. Society and adolescent self-image. Princeton: Princeton University, New Jersey Publication; 1965.

26. Hoshino A. Psychology of emotion and education. Child Psychol. 1970;24(1264-1283):1445-77 (article in Japanese).

27. Kawabata T, Ishikawa T, Katsuno S, Nishioka N, Nozu Y, Shimai $\mathrm{S}$, et al. Sexual behavior and related factors among junior and senior high school students: focusing on psychosocial variables including self-esteem. Japan J Sch Health. 2007;49:335-47 (article in Japanese).

28. Kirby DB, Baumler E, Coyle KK, Basen-Engquist K, Parcel GS, Harrist R, et al. The 'Safer Choices' intervention: its impact on the sexual behaviors of different subgroups of high school students. J Adolesc Health. 2004;35:442-52.

29. Flay BR, Graumlich S, Segawa E, Burns JL, Holliday MY. Effects of 2 prevention programs on high-risk behaviors among African American youth,a randomized trial. Arch Pediatr Adolesc Med. 2004;158:377-84.

30. Tomiko M. Effects of sexual education for junior high school students accompanied by life-skill training on knowledge, attitude and behavior. Adolescentology. 2007;25:436-44 (article in Japanese).

31. Larsson I, Svedin CG. Sexual experiences in childhood: young adults' recollections. Arch Sex Behav. 2002;31:263-73.

32. Papadopoulos NG, Stamboulides P, Triantafillou T. The psychosexual development and behavior of university students: a nationwide survey in Greece. J Psychol Human Sex. 2000;11: 93-110.

33. Hashimoto M, Maeda $H$, Ishida $T$, Takamura $H$. Evaluating program and education tools for reproductive health education used with the peer counseling method in Japanese adolescents. Adolescentology. 2007;25:321-8 (article in Japanese).

34. Takedomi Y, Ozaki I, Yamada S, Hamano K, Inoue E, Sano M, et al. A survey of sex education of students by their parents. Jpn Soc AIDS Res. 2003;5:76-81 (article in Japanese).

35. Hiraoka T. A survey on the awareness of sex and sexual education among junior high school students and their parents, high school students, and junior college students. Adolescentology. 2005;23:161-70 (article in Japanese). 